\title{
Soft Tissue Metastasis of Breast Cancer
}

\author{
Salwa Fathy ${ }^{1 *}$ and Maha Alidrisi ${ }^{2}$ \\ ${ }^{1}$ Radiation Oncology and Nuclear Department, South Egypt Cancer Institute, Assiut university, Egypt \\ ${ }^{2}$ FRCP Radiation Oncology, consultant of radiation oncology, Oncology center of King Abdullah Medical City
}

Submission: June 01, 2017; Published: June 08, 2017

"Correspondence Address: Salwa Fathy MD, Radiation Oncology and Nuclear Department, Lecturer of radiation Oncology, South Egypt Cancer Instituet, Assiut university, Egypt, Email: myhoneysalwa@yahoo.com

Abstract

Cancers that are metastasizing to soft tissue are rare. Here we present a case of metastatic breast cancer to the soft tissue of the back.

Case Report: A 64 years female patient with a history of previously completed treatment for bilateral breast cancer 3 years ago, presented with hard fixed soft tissue mass in lower part of her back on right side. CT scan of abdomen revealed a mass in right External Oblique muscle of the right lumber region. A biopsy was taken from it showed metastatic carcinoma. Thorough systemic search for the primary tumor was done. Post operative histopathology revealed metastatic mammary duct carcinoma, grade 3.

Discussion: Plaza JA et al. [1] had a series of 118 patients having metastasis to the soft tissue and out of those only 13 cases corresponds to metastasis from breast cancer and 3 of those were having metastasis to the back. However, we have not found any other report of soft tissue mass over back as a metastasis from breast cancer. We strongly suggest histological verification and systemic evaluation, whenever soft tissue masses are located elsewhere even after a curative breast cancer operation.

Conclusion: Soft tissue metastasis from breast cancer is uncommon but can present. Proper diagnosis is needed to improve the treatment outcome.

Keywords: Breast cancer; Soft tissue; Metastasis

Abbreviations: IHC: Immuno Histo Chemical; MRI: Magnetic Resonance Imaging; LVI: Lympho Vascular Invasion; ER: Estrogen Receptor; STS: Soft Tissue Sarcoma

\section{Introduction}

Cancers metastasizing to soft tissue are rare and can be easily misdiagnosed histologically for a primary softtissue sarcoma. Soft tissue is usually not the site of distant dissemination of solid tumors. However, metastasis to soft tissues can be seen in solid tumors like lungs, stomach, colon, esophagus, uterus, pancreas and haematological malignancies like lymphomas which have shown more propensities for soft tissue spread as compared to carcinoma breast [2,3]. The clinical distinction between a metastatic neoplasm to soft tissue and a primary soft-tissue malignancy is critical because treatment and prognosis are markedly different. Histopathological and immunohistochemical (IHC) analysis plays the major role in differentiating and determining the primary lesion. Till date, breast carcinomas metastasizing to soft tissue, whether skeletal muscle or subcutaneous tissue has been rarely reported [4-7]. Only few small series and isolated cases of soft tissue metastasis from breast cancer have been reported [8-14]. It has been shown that intramuscular soft tissue metastatic nodules are painful, whereas soft tissue sarcomas scarcely produce pain, but grow slowly [15]. Here we present a case of metastatic soft tissue of the back from a breast cancer. Therefore as it is considered a rare case, its early diagnosis and treatment are important for a better prognosis.

\section{Case Report}

A 64 years old post-menopausal female patient presented to our radiotherapy outpatients clinic 3 years after history of treatment of breast cancer with a painless swelling on the lower part of her back on right side for 7 months. A $6 \times 4 \mathrm{~cm}$ hard, irregular, non-tender mass, fixed to overlying skin was present $5 \mathrm{~cm}$ superior to right posterior superior iliac spine. Biopsy was taken from it, and showed metastatic carcinoma (Figure 1). The patient has a history of ten years back for bilateral Carcinoma of breast treated at National Guard Hospital, KSA. The right breast cancer with modified radical mastectomy and adjuvant chemotherapy, radiotherapy, and Letrozole as a hormonal treatment since 2007. 6 years later, she developed left breast cancer with breast conservative surgery, adjuvant 
chemotherapy, radiotherapy, and Tamoxifen as a hormonal treatment. Both postoperative histopathology examinations were moderately differentiated invasive ductal carcinoma. The immunohistochemistry showed tumor positivity to estrogen, progesterone receptors and HER-2neu.

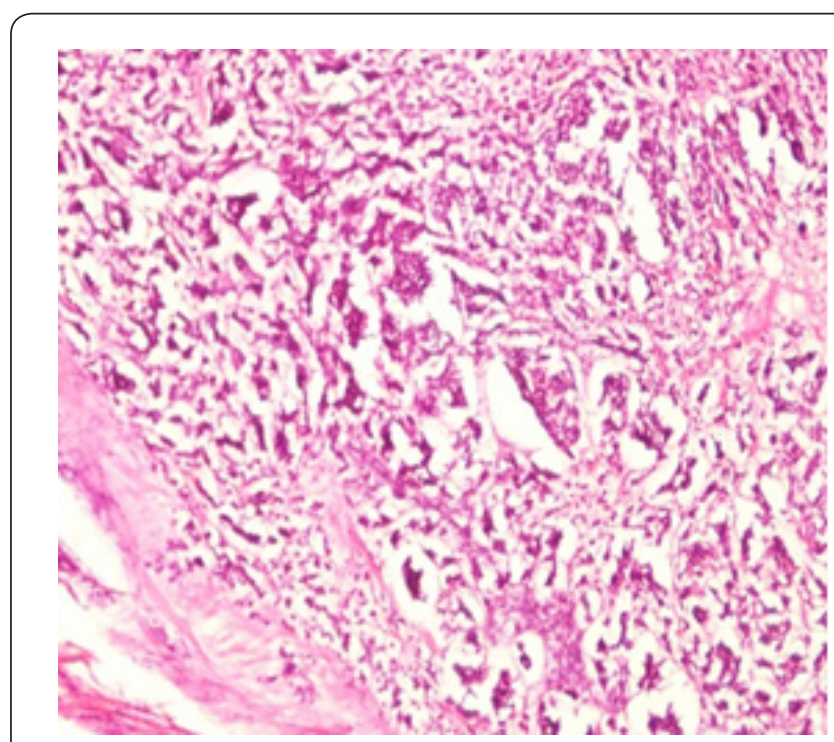

Figure 1: Biopsy of the swelling showing metastatic carcinoma (H\&E).

A thorough systemic search was then carried out to detect the primary of this soft tissue metastasis. Ultrasound of abdomen revealed normal intra-abdominal organs. An X-Ray of the chest was also normal. CT scan of abdomen revealed a mass in right External Oblique muscle in the right lumber region (Figure 2). MRI pelvis, whole body bone scan, SPECT-CT, mammography of the left breast, CT Brain, CT chest and Pap smear were also done; and all of them were normal and free of any malignancy.

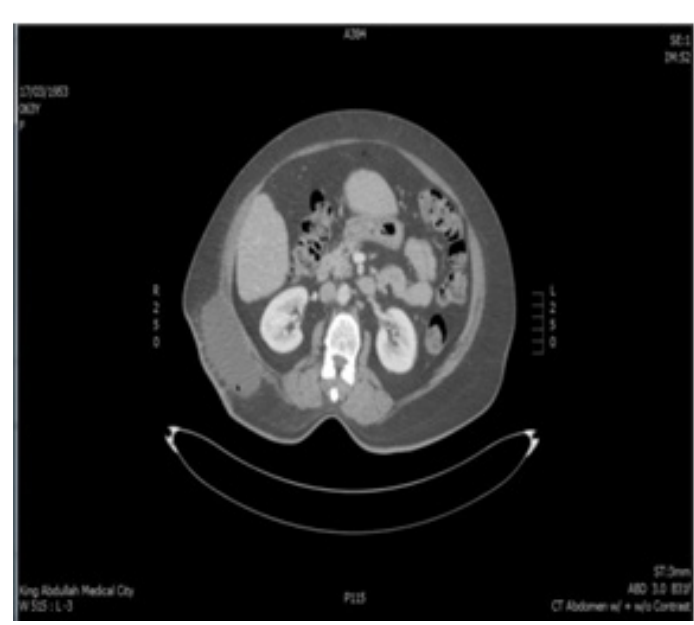

Figure 2: CT Abdomen with and without contrast shows a mass in right External Oblique muscle.

Complete surgical excision of the mass was done, and the post-operative histopathological examination showed metastatic mammary duct carcinoma, grade 3, with positive lympho-vascular invasion, and perineural invasion. To confirm its origin from breast cancer and exclude other cancer origins we did immunohistochemical stains for hormone receptors which revealed strong tumor positivity for both estrogen and progesterone receptors with positive HER-2neu (Figure 3). Other immuno-histochemical stains as Ki- 67 was $30 \%$ only, focal positivity of GCDFP-15, and negative CK 7.

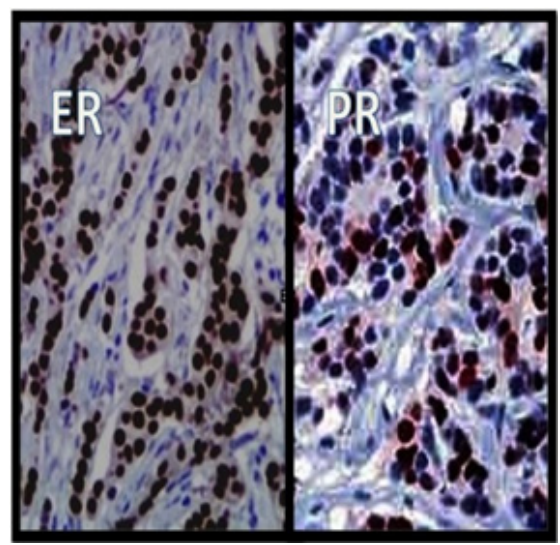

Figure 3: Immunohistochemistry (IHC) showing estrogen receptor (ER), and progesterone receptor positivity.

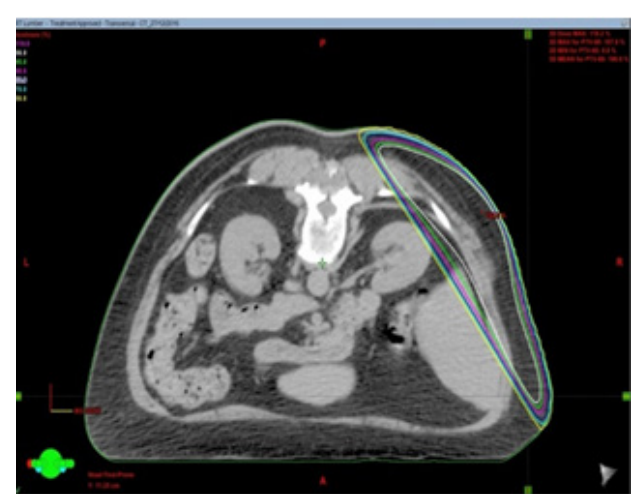

Figure 4a: Dose distributions in an axial view illustrates the color isodose lines ranges from $50 \%$ to $110 \%$ of the prescription dose.

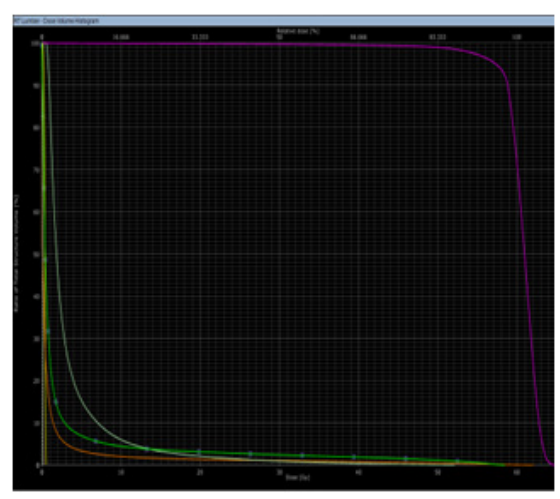

Figure 4b: DVH shows good PTV coverage with an acceptably low doses to OAR. 
Hence this soft tissue metastasis is a solitary site of metastasis in our patient which is completely surgically resected, we planned the patient for postoperative radiotherapy on tumor bed in order to prevent its recurrence for 60 Gy / 30 Fractions / 6 weeks, tangential fields in prone position. The isodose lines and DVH (Figures 4a \& 4b) show good planning target volume coverage with an acceptably low dose to organ at risk.

\section{Discussion}

Despite the finding that soft tissue comprises approximately $55 \%$ of our body mass, hematogenous metastases to these areas are rarely reported in world literature till date [2-4,10]. Direct extension of a primary tumor to soft tissue is a much more common event than distant soft tissue metastases. Breast as the primary malignancy has been reported by still fewer studies [4-6]. With regard to soft tissue metastasis, some studies have reported a frequency of $0.8 \%$ based on autopsies while few reported an incidence of $0.2 \%$ based on clinical studies [16]. This rarity can be due to the fact that soft tissues produce anticarcinogenic factors like lactic acid, beta adrenergic receptors or protease inhibitors which serve as a deterrent for metastatic invasion, in addition to other factors as changes in $\mathrm{pH}$, accumulation of metabolites, and the local temperature of soft tissue sites $[4,10]$. Soft tissue metastasis can be in subcutaneous tissue or in muscular tissue [2]. Such these local or tissue factors make it difficult for cancer cells to travel across the soft tissue [10].

Breast cancer is one of the most common cancers for women worldwide which generally metastasizes to bone, lung, liver, brain and lymph nodes, whereas soft tissue is not the usual site. As for the soft tissue metastatic sites, and thorough literature search, we were able to find only two large reports on distant soft tissue metastasis [2,1]. Plaza et al. [1] had a series of 118 patients having metastasis to the soft tissue and out of those only 13 cases corresponds to metastasis from breast cancer and 3 of those were having metastasis to the back [1]. However, we have not found any other report of soft tissue mass over back as a metastasis from breast cancer. Most of the other reported cases indicated skin, kidney, lung, colon, bone, ovary, or cervical cancer as primary tumors, with the clear exception of breast cancer.

Breast carcinoma is an aggressive disease with about $10-$ $15 \%$ patients developing distant metastasis within 3-4 years. Distant or local spread via hematogenous or lymphogenous route augers a dismal prognosis for the patient with a larger tumor size, higher grade, high lymph nodal burden and lymphovascular invasion (LVI) being the known prognostic markers. Hormone receptors studies have shown that estrogen receptor (ER) positive breast carcinomas metastasize to skeletal system, while HER 2-Neu over expression is associated with poor prognosis in auxiliary lymph node positive patients [4]. DNA microarray studies have shown that breast carcinoma is both a local and a systemic disease and it possesses the capability of early metastasis to distant sites. Gene-expression signatures and geneexpression profiling are the novel techniques which are being used to identify breast cancers patients likely to develop distant metastasis, which is the main cause of mortality. Even though many new chemotherapeutic agents and treatment modalities have led to improved survival of breast carcinoma patients, we often unexpectedly have to face distant dissemination of this ailment.

As for the initial diagnosis of any soft tissue lesion, Damron et al. [2] and Torigoe et al. [3] identified soft tissue sarcoma [STS] in $43 \%$ and $50 \%$ respectively followed by a cyst or an abscess, thus establishing STS as the primary differential diagnosis [2,3]. However metastatic soft tissue swelling will be painful due to involvement of subcutaneous tissue and skin. Most importantly, to suspect a metastatic swelling, history of any prior malignancy is important as there are no clinical or radiological similarities between them apart from histologic characteristics [2]. The main diagnostic approach for identifying soft tissue metastasis has been magnetic resonance imaging (MRI) which is now being superseded by 18-fluorodeoxyglucose whole body positron emission tomography (18-FDG WB PET CT) scan due to its higher sensitivity as most metastatic lesions have higher FDG uptake as compared to normal tissues [17]. The CT component of the scan helps localize the lesions as soft tissue metastatic lesions appear hyperdense or hypodense as compared to the surrounding soft tissues. However, only a histopathological examination of biopsy specimens verifies the diagnosis, as the metastatic lesion and the primary will have similar histological features. Further immunohistochemistry of the tissue confirms the exact site of primary lesion. Expression of desmin, CD 34, EMA, S100 indicates a STS, while immunopositivity for CK7+, and/or CK20+, TTF-1 signifies a pulmonary or gastrointestinal adenocarcinoma respectively $[1,18]$. Our case stained positive for both ER and PR while being negative for desmin, CK7, TTF-1, EMA which proved breast origin of metastasis. The diagnosis of the exact pathology is of utmost importance as the treatments of all entities are different and any misdiagnosis can result in undue morbidity or even death.

The prognosis of neglected soft tissue metastases from breast cancer has been death in a span of about five months [2]. Thus treatment of metastatic soft tissue tumors, a multimodality approach generally is adopted depending upon the performance status of the patient, any comorbid condition, type of primary malignancy, site and size of the metastatic lesion. Radiotherapy and chemotherapy have been generally considered the primary modality of therapy either in combination or separately while surgery is reserved for patients not responding to radiation or chemotherapy [2]. Damron et al. [2] reported 25\% while Torigoe et al. reported 47\% 1-year survival rate in the combined chemoradiation modality, thus indicating the poor prognosis of patients with soft tissue metastasis [2,3]. 


\section{Conclusion}

A high degree of clinical suspicion and immunohistopathological confirmation is required to identify and diagnose any soft tissue swelling over body in a previously treated breast primary to prevent any inappropriate treatment causing undue morbidity or even mortality.

\section{Ethical Considerations}

Patient's written informed consent was obtained for publication of this case report.

\section{Acknowledgement}

We would like to extend our gratitude to department of Surgical Oncology, department of Pathology and department of Radiology, KAMC, KSA.

\section{Conflicts of Interest}

The authors have no conflicts of interest to declare.

\section{References}

1. Plaza JA, Perez-Montiel D, Mayerson J (2008) Metastases to soft tissue: a review of 118 cases over a 30-year period. Cancer 112(1): 193-203.

2. Damron TA, Heiner J (2000) Distant soft tissue metastases: a series of 30 new patients and 91 cases from the literature. Ann Surg Oncol 7 (7): 526-534.

3. Torigoe T, Terakado A, Suehara Y (2011) Metastatic Soft Tissue Tumors. Journal of Cancer Therapy 2: 746-751.

4. Surov A, Hainz M, Holzhausen HJ (2010) Skeletal muscle metastases: primary tumours, prevalence, and radiological features. Eur Radiol 3 (20): 649-658.

5. Konatam ML, Triveni B, Zeesham S (2015) Soft tissue metastasis in carcinoma breast: a rare presentation. International Journal of Scientific and Research Publications 8(5): 1-7.

6. Khanna S, Prakash S, Kumar S (2013) Soft tissue metastasis in carcinoma breast: a case report. World J Pathol 2: 25-28.
7. Leinung S, Mobius C, Udelnow A, Hauss J, Wurl P (2007) Histopathological outcome of 597 isolated soft tissue tumors suspected of soft tissue sarcoma: a single-center 12-year experience. Eur J Surg Oncol 33(4): 508-511.

8. Tuoheti Y, Okada K, Osanai T (2004) Skeletal muscle metastases of carcinoma: a clinicopathological study of 12 cases. Jpn J Clin Oncol 34(4): 210-214.

9. Glockner JF, White LM, Sundaram M, McDonald DJ (2000) Unsuspected metastases presenting as solitary soft tissue lesions: a fourteen-year review. Skeletal Radiol 29(5): 270-274.

10. Herring CL Jr, Harrelson JM, Scully SP (1998) Metastatic carcinoma to skeletal muscle. A report of 15 patients. Clin Orton Relate Res 335: 272-281.

11. Yoshioka H, Itai Y, Niitsu M, (1999) Intramuscular metastasis from malignant melanoma: MR findings. Skeletal Radiol. 28[12]: 714-716.

12. Viswanathan N, Khanna A (2005) Skeletal muscle metastasis from malignant melanoma. Br J Plast Surg. 58(6): 855-858.

13. Torosian MH, Botet JF, Paglia M (1987) Colon carcinoma metastatic to the thigh an unusual site of metastasis. Dis Colon Rectum 30(10): 805808.

14. Tochigi H, Nakao Y, Horiuchi Y, Toyama Y (2000) Metastatic malignant melanoma in the hand musclea ,Hand Surg. 5(1): 69-72.

15. Sudo A, Ogihara Y, Shiokawa Y, Fujinami S, Sekiguchi S (1993) Intramuscular metastasis of carcinoma. Clin Orthop Relat Res 296 : 213-217.

16. James JJ, Evans AJ, Pindar SE (2003) Bone metastases from breast carcinoma: histopathological-radiological correlations and prognostic features. Br J Cancer 89(4): 660-665.

17. Pfannenberg C, Aschoff P, Schanz S (2007) Prospective comparison of 18F-fluorodeoxyglucose positron emission tomography/computed tomography and whole-body magnetic resonance imaging in staging of advanced malignant melanoma. Eur J Cancer 43(3): 557-564.

18. Tot T (2002) Cytokeratins 20 and 7 as biomarkers: usefulness in discriminating primary from metastatic adenocarcinoma. Eur J Cancer 38(6): 758-763.

\section{Your next submission with Juniper Publishers} will reach you the below assets

- Quality Editorial service

- Swift Peer Review

- Reprints availability

- E-prints Service

- Manuscript Podcast for convenient understanding

- Global attainment for your research

- Manuscript accessibility in different formats

( Pdf, E-pub, Full Text, Audio)

- Unceasing customer service

Track the below URL for one-step submission https://juniperpublishers.com/online-submission.php 